\title{
3D-CFD Simulation of Confined Cross-Flow Injection Process Using Single Piston Pump
}

\author{
Mohamed Elashmawy \\ Mechanical Engineering Department \\ University of Hail, Saudi Arabia and \\ Engineering Science Department \\ Faculty of Petroleum and Mining Engineering \\ Suez University, Suez, Egypt \\ arafat_696@yahoo.com
}

\begin{abstract}
Injection process into a confined cross flow is quite important for many applications including chemical engineering and water desalination technology. The aim of this study is to investigate the performance of the injection process into a confined cross-flow of a round pipe using a single piston injection pump. A computational fluid dynamics (CFD) analysis has been carried out to investigate the effect of the locations of the maximum velocity and minimum pressure on the confined crossflow process. The jet trajectory is analyzed and related to the injection pump shaft angle of rotation during the injection duty cycle by focusing on the maximum instant injection flow of the piston action. Results indicate a low effect of the jet trajectory within the range related to the injection pump operational conditions. Constant cross-flow was used and injection flow is altered to vary the jet to line flow ratio $\left(Q_{R}\right)$. The maximum jet trajectory exhibits low penetration inside the cross-flow. The results showed three regions of the flow ratio effect zones with different behaviors. Results also showed that getting closer to the injection port causes a significant decrease on the locations of the maximum velocity and minimum pressure.
\end{abstract}

Keywords-3D-CFD; injection process; cross-flow; single piston

\section{INTRODUCTION}

Cross-flow Injection is an important process for many applications. Injection facility is essential plyer in this process. The most widely used type worldwide is the diaphragms pump type because of its simple and compact design with relatively low cost compared to other types. The disadvantage of this type is mainly due to its diaphragm material which subjected to intensive cyclic fatigue at certain points. Many researches focused on the performance and design of the diaphragm pumps. To minimize diaphragm fatigue, hydraulically actuated diaphragm pumps are usually used. Variable-speed drive is one of the controlling facilities used for such type. However using pneumatic diaphragm pumps is not sufficient to overcome the diaphragm material failure [1]. Low cost is the main advantage of this pump type from long time ago and still the main motivation for its attractiveness. For high pressure injection application piston injection pumps are adequate device. Some effort was done establishing a new injection concept based on line bleeding that is able to satisfy both high and low pressure requirements according to the pressure inside the line. The new concept requires no rotating parts having simple and compact design with very low cost $[2,3]$. Injection process into crossflow enhances flow characteristics. Increasing the velocity of the cross-flow injection gradually reduces Reynolds number and some other parameters. Moreover the penetration of the jet in the cross-flow satisfies more than twice stronger and better mixing conditions than the jet in the co-flow case $[4,5]$. The shear layer and vortices of the wake field near the wake region of the jet are very important to stabilize the chemical reaction and enhance the gas turbine performance [6]. Using multilateral jets upstream from the exit of the nozzle helps to control the mixing field of the combustor [7]. When using two jets in cross-flow injection process, the two jets will merge into a single trajectory after mixed with the cross-flow. Two tandem jets have more potential than one jet to penetrate deeper in the cross-flow. The rear jet penetrates deeper than the front jet because of the front jet simply shielded it $[8,9]$. A research was performed concerning a classification of the turbulent jet mechanics of a T-junction for cooling systems in power plants. Results provided optimum operating conditions of the $\mathrm{T}$ junction in a real field of Phoenix reactor showing the importance of a $90^{\circ}$ bend component which enhances the mixing process mechanism. Furthermore a visualization test-rig system with three separated sections to enable each section to be visualized separately with the particle image velocimetry (PIV). Three mixing regions appear accompanied by maximum velocity fluctuations: (1) close to the jet boundary, (2) above the jet (along the cross-flow), and (3) near the wake downstream area above the jet. Region (3) is the strongest one which has a higher cycle thermal fatigue [10, 11]. A CFD simulation was performed based on the momentum ratio for $\mathrm{T}$ junctions with different angles. The cross-flow angle with injection direction significantly affected the velocity ratio and it is important for improving the design of piping systems [12]. In cases when the mixing process has laminar flow, the mixing process becomes difficult. The pulsation and geometry effect on the mixing process within a microchannel was experimentally and numerically investigated. The results show that the geometry of the mixing region strongly affects the 
mixing quality. $\mathrm{T}$ and arrowed intersection geometries showed the best efficiency for the mixing process, while the singleright angle intersection showed the worst mixing behavior. A mixing enhancement of $71.9 \%$ could be reached for the singleright angle intersection when using flow pulsation while $153 \%$ mixing enhancement was reached by using a combination of flow pulsation and geometry effects [13]. Recently a research work studied the effect of the size of the pipe lines (cross-flow pipe) on the cross-flow injection characteristics showing the importance of this parameter on enhancing the injection process and the design of the pipelines. Results show that increasing pipeline size enhances injection pump dose by almost $3.24 \%$ at full pump displacement [14]. The aim of the current study is to predict the behavior of the locations of the maximum velocity and minimum static pressure within the injection process into a confined cross-flow. A computational fluid dynamics (CFD) analysis is performed and related to the instantaneous injection flow rates of a single piston pump driven by circular cam action. This study is a further research effort to continue the experimental work performed before in [14].

\section{CFD CROSS-FLOW INJECTION SIMULATION}

The cross-flow injection behavior is analyzed using 3DCFD (ANSYS-Fluent). Figure 1 shows a schematic diagram of the test section geometry. Both line flow (cross-flow) and injection flow (jet-flow) are water (isothermal mixing process). Water viscosity changes by $0.535 \%$ as the pressure change from 1 to $10 \mathrm{MPa}$ [15]. It is convenient to use a constant viscosity and density of $1.003 \times 10^{-3} \mathrm{~Pa} . \mathrm{s}$ and $998.2 \mathrm{~kg} / \mathrm{m}^{3}$ respectively for both injection and cross-flow (injection) water streams. A constant line flow rate of $83.33 \times 10^{-3} \mathrm{~kg} / \mathrm{s}$ is used (similar to reference [14]). Reynolds numbers are 6612, 7157 and 9918 for $Q_{R}=0,8.25 \%$ and $50 \%$ respectively. A standard $k$ $\varepsilon$ turbulent flow model is included. Table I shows the boundary conditions and the solution settings used for numerical solution operated by 3D-CFD (ANSYS-Fluent). Table II shows the mesh independence of the CFD, 1.2 mesh size was selected with accuracy of $0.013 \%$ which is accepted to reduce time of calculations (70154 nodes and 182012 elements). Figure 2 shows the convergence curves of the iteration parameters of the numerical calculations. The convergence attained after 259 iterations using hybrid initialization. Figure 3 shows the duty cycle of the single piston injection pump. The maximum indicating injection flow is $6.875 \times 10^{-6} \mathrm{~m}^{3} / \mathrm{s}(594 \mathrm{~L} /$ day $)$ and occurred at $\alpha=113^{\circ}$ shaft angle. The duty cycle is occurred from
0 to $\alpha=180^{\circ}$ while from $\alpha=180^{\circ}$ to $\alpha=360^{\circ}$ injection duty stopped and suction duty started.

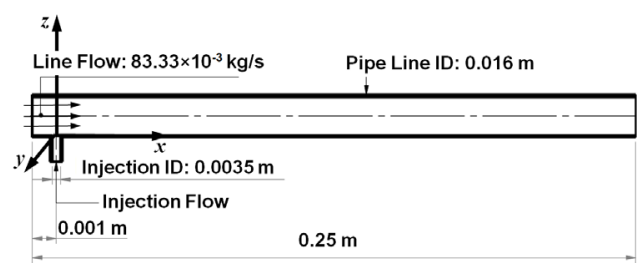

Fig. 1. Schematic diagram of the CDF test-section.

TABLE I. BOUNDARY CONDITION AND SOLUTION METHOD

\begin{tabular}{|c|c|c|c|}
\hline \multicolumn{2}{|c|}{ Boundary Conditions } & \multicolumn{2}{|c|}{ Solution Method (default) } \\
\hline Water density & $998.2\left(\mathrm{~kg} / \mathrm{m}^{3)}\right.$ & Scheme & Simple \\
\hline Water viscosity & $\begin{array}{c}1.003 \times 10^{-3} \\
\mathrm{~kg} / \mathrm{m} . \mathrm{s}\end{array}$ & Gradient & $\begin{array}{c}\text { Least square, } \\
\text { cell based }\end{array}$ \\
\hline $\begin{array}{c}{ }^{\mathrm{a}} \text { Injection Inlet } \\
\text { Water, (mass flow) }\end{array}$ & $6.875 \times 10^{-3} \mathrm{~kg} / \mathrm{s}$ & Pressure & Second order \\
\hline $\begin{array}{c}\text { Line Inlet } \\
\text { Water, (mass flow) }\end{array}$ & $\begin{array}{c}83.333 \times 10^{-3} \\
\mathrm{~kg} / \mathrm{s}\end{array}$ & Momentum & $\begin{array}{c}\text { Second order } \\
\text { upwind }\end{array}$ \\
\hline $\begin{array}{c}\text { Outlet } \\
\text { (Gauge Pressure) }\end{array}$ & $0 \mathrm{~Pa}$ & $\begin{array}{c}\text { Turbulent } \\
\text { kinetic energy }\end{array}$ & $\begin{array}{l}\text { First order } \\
\text { upwind }\end{array}$ \\
\hline Wall & No slip & $\begin{array}{c}\text { Turbulent } \\
\text { dissipation rate }\end{array}$ & $\begin{array}{l}\text { First order } \\
\text { upwind }\end{array}$ \\
\hline
\end{tabular}

a. Injection inlet varies according to $Q_{R}$ (here is the value according to $Q_{R}=8.25 \%$; at $\alpha=113^{\circ}$ ).

\section{RESULTS AND DISCUSSION}

Results are based on steady flow in order to introduce an insight of the cross-flow injection process and look at the behavior of the injection in a confined cross-flow process, (JICCF) which is not experimentally performed in this work. Figure 4 shows the CFD velocity contours related to pump shaft angle $(\alpha)$ of Fig. 3. $Q_{R}$ increased from zero to $8.25 \%$ with shaft angles from $\alpha=$ zero to $\alpha=113^{\circ}$ then decreases to zero again from $\alpha=113^{\circ}$ to $\alpha=180^{\circ}$. There are no injection occurred at $\alpha=$ zero and $\alpha=180^{\circ}$. Figure 5 shows the jet trajectory for various shaft angles. Increasing the flow ratio (jet velocity) increases the jet penetration ability (z-direction) and leads to a longer distance in the axial direction (x-direction) that is fully mixed with the cross-flow, causing a stronger wake behind the jet. In order to better understand the behavior of the JICCF, a 3D-CFD study is performed for the maximum jet action case ( $\left.Q_{R}=8.25 \%\right)$ occurring at shaft angle $\alpha=113^{\circ}$ to evaluate how the velocity and static pressure behave along the axial flow (cross-flow stream) at 3-different radial distances (centerline, $z / D=1.3$ and $z / D=0.3)$.

TABLE II. MESH INDEPENDENCE

\begin{tabular}{|c|c|c|c|c|c|c|c|}
\hline \multirow{2}{*}{$\begin{array}{l}\text { Element size } \\
\qquad(\mathrm{mm})\end{array}$} & \multirow{2}{*}{ Nodes } & \multirow{2}{*}{ Elements } & \multirow{2}{*}{ Iterations } & \multicolumn{2}{|c|}{ Maximum Velocity (m/s) } & \multicolumn{2}{|c|}{ Minimum Pressure (Pa) } \\
\hline & & & & Centerline & $Z / D=0.3$ & Centerline & $Z / D=0.3$ \\
\hline 2.0 & 25493 & 61649 & 300 & 0.53 & 0.66 & 59.66 & -74.37 \\
\hline 1.8 & 30312 & 73711 & 350 & 0.53 & 0.78 & 60.37 & -66.45 \\
\hline 1.6 & 38928 & 96489 & 400 & 0.54 & 0.77 & 57.46 & -65.29 \\
\hline 1.4 & 49279 & 122914 & 500 & 0.53 & 0.76 & 57.42 & -65.19 \\
\hline 1.2 & 70154 & 182012 & 259 & 0.53 & 0.83 & 57.81 & ${ }^{\mathrm{a}}-77.29$ \\
\hline 1.0 & 103511 & 270633 & 286 & 0.53 & 0.83 & 57.81 & -77.30 \\
\hline 0.8 & 163841 & 455125 & 325 & 0.53 & 0.83 & 57.81 & -77.30 \\
\hline
\end{tabular}




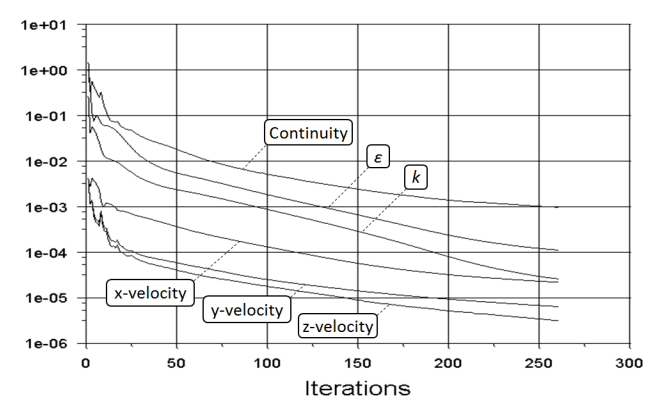

Fig. 2. Convergence curves of the CFD iterations.

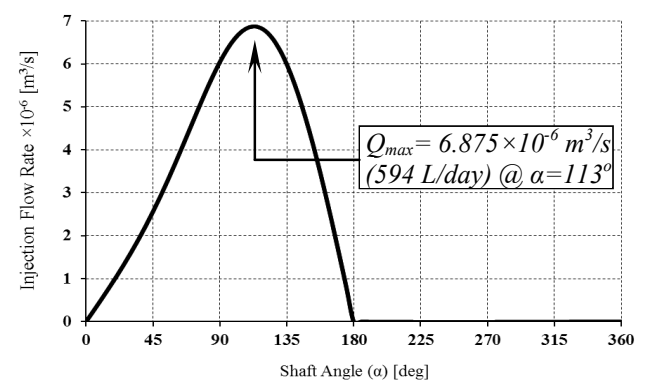

Fig. 3. Injection duty cycle of the single piston action.

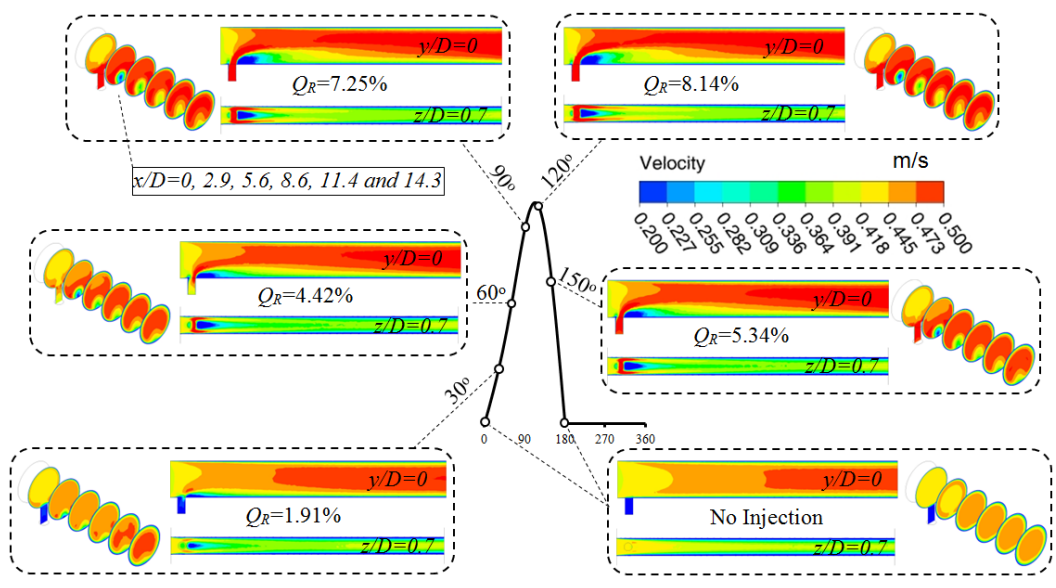

Fig. 4. CFD velocity contours related to pump shaft angle $(\alpha)$ of Fig. 3.

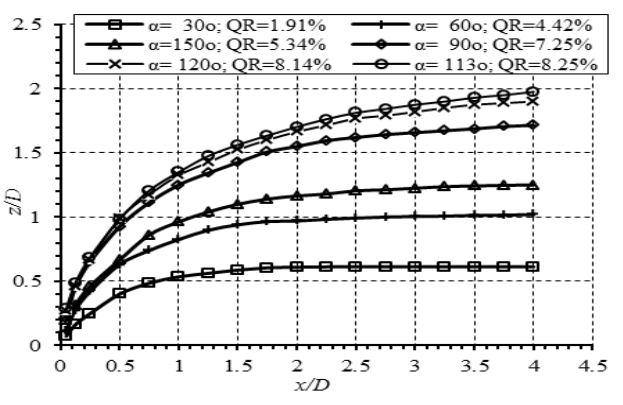

Fig. 5. Jet trajectory of the confined cross-flow injection for 6-shaft angles of the VDRIP.

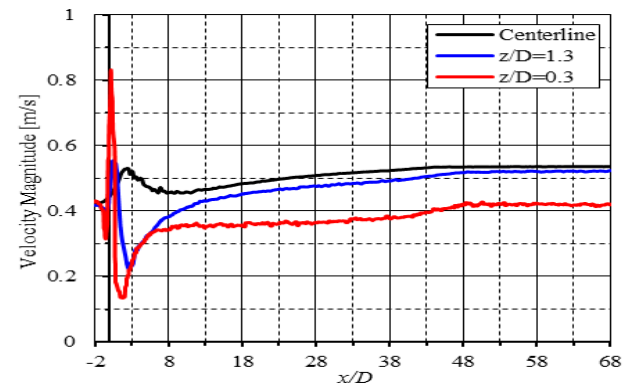

Fig. 6. Velocity magnitude distribution in the axial direction of the cross-flow, $Q_{R}=8.25 \%$.

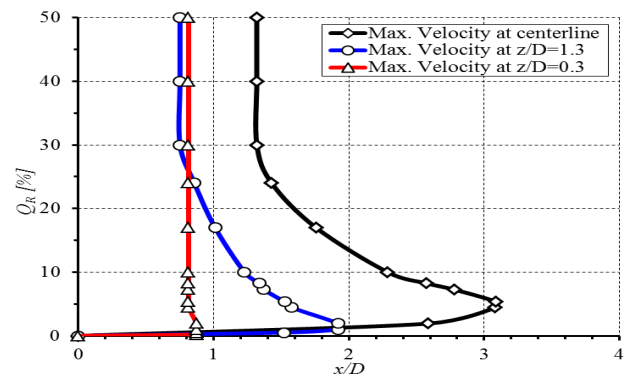

Fig. 7. Position of the maximum velocity magnitude in the axial flow direction for a wide range of flow ratios $\left(Q_{R}\right)$.

Figure 6 shows the velocity magnitude distribution in the $\mathrm{x}$-direction. Curves show a significant increase in the axial velocity directly after the injection port $(\mathrm{x} / \mathrm{D}=0)$ followed by a significant decrease forming two peaks (maximum and minimum) at the pipe centerline. Three peaks appeared when getting closer to the jet port minimum; before injection, a maximum occurred directly after injection, and then a minimum occurred again after that. Figure 7 shows the effect of the flow ratio $\left(Q_{R}\right)$ on the position of the maximum velocity magnitude along the x-direction where it is expected to have a wake region. A wider range of $Q_{R}$ is studied in order to show the effect of $Q_{R}$ on the position of the maximum velocity including the pump operational range $(0-8.25 \%)$. The curves show three effect regions (similar to the three regions obtained 
by [11]). Region (1) is a very narrow region with a range of $Q_{R}$ from 0 to almost 5\% as maximum, wherein increasing the $Q_{R}$ sharply increases the location of the maximum velocity to $x / D=3.08,1.92$ and 0.87 for centerline, $z / D=1.3$ and $z / D=0.3$ respectively. In region (2), $\left(Q_{R}=5 \%\right.$-30\%) increasing the $Q_{R}$ decreases the location of the maximum velocity to $x / D=1.32$, 0.75 and 0.81 for centerline, $z / D=1.3$ and $z / D=0.3$ respectively. In region (3), $\left(Q_{R}>30 \%\right) \quad Q_{R}$ has no significant effect. Moreover, getting closer to the jet port $(z / D=1.3$ and 0.3$)$ decreases the location of the maximum velocity magnitude, indicating the strong effect of the jet action on the cross-flow stream. Figure 8 shows the distribution of the static pressure along the x-direction for three different z-levels. The same general behavior of Fig. 6 is obtained with slight differences in the location positions; the minimum static pressure is sharper and much closer to the jet portion. Similar behavior as in Fig. 7 is obtained in Fig. 9, showing greater position ranges. In region (1), increasing the $Q_{R}$ sharply increases the location of the minimum static pressures to $x / D=7.9,2$ and 1.1 for centerline, $z / D=1.3$ and $z / D=0.3$ respectively. In region (2), increasing $Q_{R}$ decreases the location of the minimum static pressures to $x / D=1.32,0.75$ and 0.81 for centerline, $z / D=1.3$ and $z / D=0.3$ respectively. In region (3), $Q_{R}$ has no effect on the location of the minimum static pressure. It is observed that the same locations were obtained for the maximum velocity and minimum static pressure (Figs. 7 and 9) for $z / D=1.3$ and 0.3 while the location increased for the minimum static pressure at the centerline. Figure 10 shows JICCF velocity contours and vectors. $A$ : shows the velocity contours at the $x-z$ plane followed by five sectional views at different levels parallel to the $x-y$ plane at $z / D=0.3,0.7,1.3,1.9$, and 2.3 (centerline). The wake region is very clear at $z / D=0.3,0.7$ and 1.3 locations. $B$ : shows velocity vectors similar to $(A)$ focusing on the jet action region. $C$ : shows the stream lines of the jet separated from the cross-flow focusing on the trajectory path of the jet action injected into the confined cross-flow; the performance of the jet trajectory shows low penetration inside the cross-flow (lower than the pipe centerline. $D$ : shows the wake region and the two counter rotating vortex pairs occurring at $x / D=1$. E: shows a cross sectional view of the velocity contours. Eleven equally spaced positions are introduced to show the jet mixing propagation behavior. The results obtained by Fig. 10 (D) are consistence with the results obtained in $[11,16,17]$. Also the results obtained by Fig. 10 (B and $\mathrm{C}$ ) are consistence with the results obtained in [12].

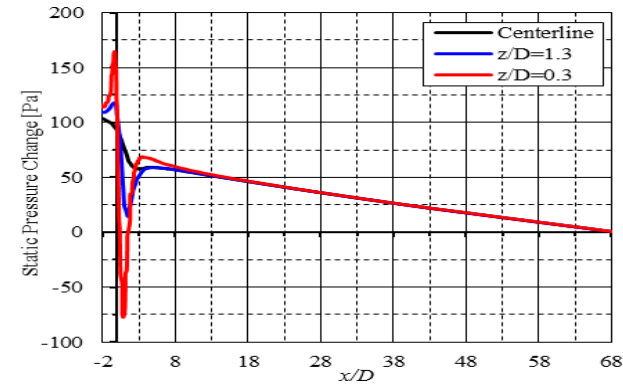

Fig. 8. Static pressure distribution along the cross-flow pipe, $Q_{R}=8.25 \%$.

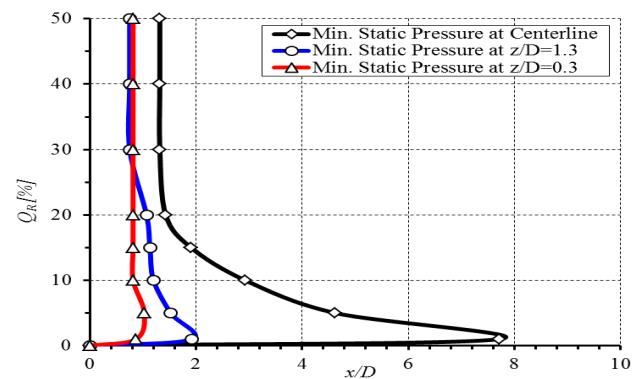

Fig. 9. Position of the minimum static pressure magnitude in the axial flow direction for a wide range of flow ratios $\left(Q_{R}\right)$.
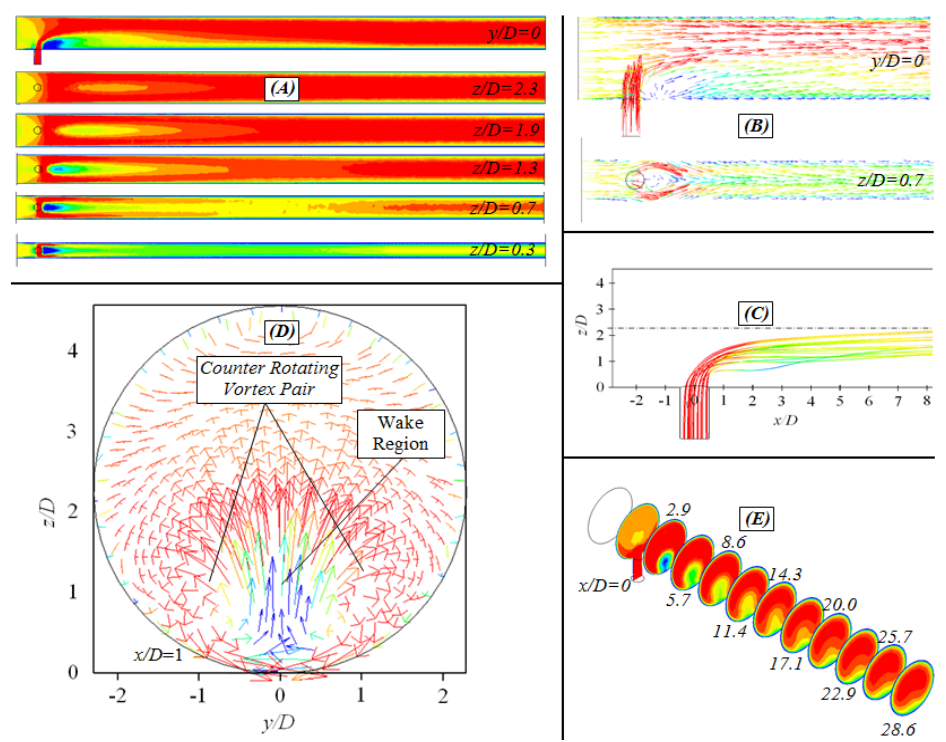

Fig. 10. CFD analysis at $\alpha=113^{\circ}\left(Q_{R}=8.25 \%\right)$; (A, B and C): velocity contours, vectors and streamlines along the pipeline flow direction, (D and E): velocity vectors and velocity contours across pipeline flow. 


\section{CONCLUSIONS}

CFD analysis of the jet action into a confined cross-flow has been performed and related to instantaneous flow rates indicated by shaft angle variation of a single piston injection pump. The analysis also focused on the maximum indicated injection flow rate in the case when $Q_{R}=8.25 \%$ at $\alpha=113^{\circ}$. The effect of the flow ratio $\left(Q_{R}\right)$ on the position of the maximum velocity magnitude and minimum static pressure along the $x$ direction is also studied. A wider range of $Q_{R}$ is considered. The results obtained by the 3D-CFD analysis showed a relatively small injection trajectory impact on the cross-flow within the injection flow range of the operational conditions of $83.33 \times 10^{-6} \mathrm{~m}^{3} / \mathrm{s}$ line flow, $1.283 \times 10^{-6} \mathrm{~m}^{3} / \mathrm{s}$ average injection flow and $6.875 \times 10^{-6} \mathrm{~m}^{3} / \mathrm{s}$ maximum instant injection flow. All jet trajectory curves show low penetration inside the crossflow, and lay under the centerline of the pipeline. CDF results showed the 3-regions of the flow ratio effect on the maximum velocity locations along the $x$-direction (consistent with [11]). The first region is a very narrow region with a maximum $5 \%$ $Q_{R}$, the second region has $Q_{R}=5 \%-30 \%$, and the third region has $Q_{R}>30 \%$. The same behave is obtained for the locations of the minimum static pressure. Getting closer to the injection centerline significantly decreases the location positions of the maximum velocity and the minimum static pressure. Increasing $Q_{R}$ sharply increases the locations for the first region and decreases it for the second region while the third region indicates no significant effect. The results of the present study show that the locations of the maximum velocity and minimum static pressure are strongly related to $Q_{R}$. Indicating that the location parameter could be the key point for designers beside the values of the maximum velocity and minimum static pressure.

Further research efforts are recommended including the following:

- An experimental study of the same test section and parametric conditions is highly recommended validating the CFD results.

- Using a user defined boundary (UDF) condition at the inlet would be more realistic.

\section{ACKNOWLEDGMENT}

Acknowledgments are due to the Deanship of Scientific Research, University of Hail, KSA for funding and supporting this project with code (E5-ME 2014) and making it feasible.

\section{REFERENCES}

[1] V. A. Kurteev, "Diaphragms for pneumatic pumps", Chemical and Petroleum Engineering, Vol. 47, No. 78, pp. 550-556, 2011

[2] M. Elashmawy, "Novel Injection Concept: Line Bleeding Injection Pump (LBIP)", Science Innovation Vol. 2, No. 4 pp. 37-42, 2014

[3] M. Elashmawy, M. Alnais, "Developed Design for Line Bleeding Injection Pump: Double-Act LBIP”, International Journal of Mechanical Engineering and Applications, Special Issue: Advanced Fluid Power Sciences and Technology, Vol. 3, No. 5, pp. 11-16, 2015
[4] S. Majumder, D. Sanyal, "Relaminarization of Axisymmetric Turbulent Flow with Combined Axial Jet and Side Injection in a Pipe", Journal of Fluids Engineering, Vol. 132, No. 10, p. 101101, 2010

[5] C. Cardenas, J. A. Denev, R., Suntz, H. Bockhorn, "Study of parameters and entrainment of a jet in cross-flow arrangement with transition at two low Reynolds number", Experiments in Fluids, Vol. 53, No. 4, pp. 965 987, 2012

[6] P. P. Panda, M. Roa, P. Szedlacsek, W. R. Laster, R. P. Lucht, "Structure and dynamics of the wake of a reacting jet injected into a swirling, vitiated crossflow in a staged combustion system", Experiments in Fluids, Vol. 56, No. 21, 2015

[7] C. X. Thong, P. A. M. Kalt, B. B. Dally, C. H. Birzer, "Flow dynamics of multi-lateral jets injection into a round pipe flow", Experiments in Fluids, Vol. 56, No. 15, 2015

[8] T. H. New, B. Zang, "On the trajectory scaling of tandem twin jets in cross-flow in closed proximity", Experiments in Fluids, Vol. 56, No. 200, 2015

[9] E. J. Gutmark, I. M. Ibrahim, S. Murugappan, "Dynamic of single and twin circular jets in cross flow", Experiments in Fluids, Vol. 50, pp. 653663,2011

[10] S. M. Hosseini, H. Yuki, H. Hashizume, "Classification of Turbulent Jets in a T-Junction Area With a 90-deg Bend Upstream”, International Journal of Heat and Mass Transfer, Vol. 51, No. 9-10, pp. 2444-2454, 2008

[11] S. M. Hosseini, K. Yuki, H. Hashizume, "Experimental Investigation of Flow Field Structure in Mixing Tee", Journal of Fluids Engineering, Vol. 131, No. 5, p. 051103, 2009

[12] S. Qian, J. Frith, N. Kasahara, "Classification of Flow Patterns in Angled T-Junctions for the Evaluation of High Cycle Thermal Fatigue", Journal of Pressure Vessel Technology, Vol. 137, No. 2, p. 021301, 2014

[13] H. Ammar, A. Ould El Moctar, B. Garnier, H, Peerhossaini, "Flow Pulsation and Geometry Effects on Mixing of Two Miscible Fluids in Microchannels", Journal of Fluids Engineering, Vol. 136, No. 12, p. 121101,2014

[14] M. Elashmawy, A. Alghamdi, I. Badawi, "Investigation of the Effect of Pipeline Size on the Cross-flow Injection Process". Engineering, Technology \& Applied Science Research, Vol. 6, No. 3, pp. 1023-1028, 2016

[15] J. W. Schmelzer, E. D. Zanotto, V. M Fokin, "Pressure dependence of viscosity", Journal of Chemical Physics, Vol. 122, p. 074511,2005

[16] P. K. Selvam, R. Kulenovic, E. Laurien, "Experimental and numerical analyses of turbulent mixing of coolant streams in a mixing tee", Fourth International Conference on Fatigue of Nuclear Reactor Components, Seville, Spain, 2016

[17] B. Krumbein, S. Jakirlic, V. Termini, A. Mizobuchi, C. Tropea, "Flow and heat transfer in cross-stream type T-junctions: A computational study", $10^{\text {th }}$ International Symposium on Turbulence and Shear Flow Phenomena (TSFP10), Chicago, USA, July, 2017 